\title{
The Effects of Mg Deficiency on Activities and Isoenzyme Patterns of Antioxidant Enzymes in Cotton Roots
}

\author{
Rengin Ozgur Uzilday* \\ Department of Biology, Faculty of Science, Ege University, Bornova, Izmir, 35100, Turkey \\ *rengin.ozgur@ege.edu.tr \\ Received: 06 February 2019 \\ Accepted: 10 May 2019 \\ DOI: $10.18466 /$ cbayarfbe.523259
}

\begin{abstract}
Magnesium ( $\mathrm{Mg}$ ) is an essential nutrient that takes vital roles in biochemical processes related to energy metabolism, regulation of enzyme activity, nucleic acid biosynthesis and carbohydrate metabolism. $\mathrm{Mg}$ deficiency in arable lands is an emerging problem. Loss of balance in different metabolic pathways due to $\mathrm{Mg}$ deficiency causes increased production of reactive oxygen species (ROS) such as $\mathrm{O}_{2}{ }^{-}, \mathrm{H}_{2} \mathrm{O}_{2}$ and $\mathrm{HO}$ in the roots. The aim of this work was to elucidate the antioxidant response of roots of cotton (Gossypium hirsutum) to $\mathrm{Mg}$ deficiency. For this aim, antioxidant enzyme activities were measured and changes in their isoenzymes were determined. In addition, NADPH oxidase (NOX) activity was investigated to determine the changes in ROS signaling. Moreover, $\mathrm{H}_{2} \mathrm{O}_{2}$ and lipid peroxidation levels were also measured as an indicator of oxidative damage. Findings of this work indicate that $\mathrm{Mg}$ deficiency does not cause oxidative load in roots of Gossypium hirsutum plants that overwhelms cellular antioxidant defence system, as evident by $\mathrm{H}_{2} \mathrm{O}_{2}$ and TBARS levels. However, to adjust to the new redox status, root cells drastically downregulate NOX dependent ROS production and induced total superoxide dismutase activity. These findings indicate that site of $\mathrm{O}_{2}{ }^{--}$production is mitochondria in roots. Although, catalase and ascorbate peroxidase activities were decreased with $\mathrm{Mg}$ deficiency induced peroxidase activity seems to limit $\mathrm{H}_{2} \mathrm{O}_{2}$ accumulation. These adaptive responses and changes in antioxidant defence were sufficient to prevent excess ROS accumulation and occurrence of oxidative damage in roots of Gossypium hirsutum plants under Mg deficiency.
\end{abstract}

Keywords: Antioxidant defense system, antioxidant enzymes, cotton, Gossypium hirsutum, magnesium deficiency, reactive oxygen species.

\section{Introduction}

Magnesium (Mg) is an essential plant nutrient that takes vital roles in various biochemical processes in plant cells. $\mathrm{Mg}$ deficiency in arable lands is an emerging problem, especially in soils that are mainly fertilized with N, P, K. This practice causes gradual removal of $\mathrm{Mg}$ from the soil and decrease plant productivity in the long term [1]. In plants, $\mathrm{Mg}$ takes role in conformational stabilization of nucleic acids, proteins, cell membranes and cell walls. Moreover, it acts as a cofactor for various enzymes and is also vital for chlorophyll biosynthesis and function since chlorophyll contains $\mathrm{Mg}$ in the porphyrin ring. $\mathrm{Mg}$ deficiency decreases photosynthetic efficiency, phloem loading and due to this root to shoot partitioning of resources in plants [1]. In roots, $\mathrm{Mg}$ takes role in biochemical processes related to energy metabolism, regulation of enzyme activity, nucleic acid biosynthesis and carbohydrate metabolism. Loss of balance in different metabolic pathways due to $\mathrm{Mg}$ deficiency, especially that are related to energy metabolism, causes increased production of reactive oxygen species (ROS) such as $\mathrm{O}_{2}^{--}, \mathrm{H}_{2} \mathrm{O}_{2}$ and $\mathrm{HO}$ in the roots, which are produced at low levels during normal cellular function as byproducts of oxygenic metabolism [2]. The main site of ROS production in root cells is the mitochondria, where electron transport chain (ETC) related to oxidative phosphorylation is located. Overloading of mitochondrial ETC causes production of $\mathrm{O}_{2}{ }^{--}$due to transfer of electrons to molecular oxygen. If unchecked, excess levels of ROS accumulation can cause oxidative damage to proteins, lipids and nucleic acids [3]. To prevent accumulation of ROS, plants employ a variety of enzymatic and non-enzymatic antioxidants. Superoxide dismutases (SODs) are responsible for detoxification of $\mathrm{O}_{2} \cdot{ }^{--}$to $\mathrm{H}_{2} \mathrm{O}_{2}$. Resulting $\mathrm{H}_{2} \mathrm{O}_{2}$ can be converted to $\mathrm{H}_{2} \mathrm{O}$ by catalases (CATs), ascorbate peroxidases (APXs) and various peroxidases (POXs). Non-enzymatic antioxidants comprise low molecular weight antioxidants such as ascorbate, glutathione and carotenoids. ROS can also act as signal molecules at low levels and due to this they are named as dual molecules (having both damaging and signaling function). NADPH oxidases (NOX) are responsible for production of $\mathrm{O}_{2} \cdot-$ at the plasma membrane for signaling purposes [3]. 
Effects of Mg deficiency on antioxidant defense enzyme activities in photosynthetic tissues were previously investigated in Zea mays [4] and, Morus alba [5]. In Zea mays, SOD, CAT and APX and activities were induced by $\mathrm{Mg}$ deficiency, although $\mathrm{H}_{2} \mathrm{O}_{2}$ content was not changed [4]. Furthermore, $\mathrm{Mg}$ deficiency increased the activities of POX and APX in Morus alba [5]. Moreover, we have previously investigated how cotton leaves respond to $\mathrm{Mg}$ deficiency and found that SOD, CAT, POX, APX, GR, and glutathione-S-transferase (GST) activities were induced, while NOX activity was inhibited in plants grown under $\mathrm{Mg}$ deficiency [2]. Besides, striking differences were observed in SOD, NOX, POX, and GST isoenzyme patterns. As it can be seen, vast amount of work has focused on investigating response of leaves to $\mathrm{Mg}$ deficiency, however knowledge on response of antioxidant defense of roots is very limited and there is no such work in Gossypium hirsutum. Therefore, the aim of this work was to elucidate the antioxidant response of roots of Gossypium hirsutum to $\mathrm{Mg}$ deficiency. For this aim, SOD, CAT, POX, APX, GR and GST activities were measured and changes in their isoenzymes were determined. In addition, NOX activity and isoenzyme pattern were investigated to determine the changes in ROS signaling. Moreover, $\mathrm{H}_{2} \mathrm{O}_{2}$ and lipid peroxidation levels were also measured as an indicator of oxidative damage.

\section{Materials and Methods}

\subsection{Materials}

Cotton (Gossypium hirsutum) Nazilli 84-S cultivar was used in this work as plant material which was obtained from Nazilli Cotton Research Institute (NCRI) (Nazilli, Aydin, Turkey).

\subsection{Methods}

\subsubsection{Growth conditions and treatments}

Plant was grown in a hydroponic system with Hoagland solution containing $1000 \mu \mathrm{M} \mathrm{Mg}$ (sufficient), $150 \mu \mathrm{M}$ $\mathrm{Mg}$ (low), $75 \mu \mathrm{M} \mathrm{Mg}$ (deficient) and no additional $\mathrm{Mg}$ supplement (named as 1000, 150, 75 and $0 \mathrm{Mg}$ throughout the manuscript). Plants were grown in a growth chamber with $450 \mu \mathrm{E}$ light intensity, 16/8 light/dark period, $24 / 20{ }^{\circ} \mathrm{C}$ day/night temperatures and $60 \%$ relative humidity. Plants were germinated and grown at the mentioned solutions and were harvested after 3 weeks. $\mathrm{SO}_{4}$ in $\mathrm{Mg}$ deficient plants was complemented with $\mathrm{K}_{2} \mathrm{SO}_{4}$. Hoagland solutions were changed every three days. Roots were flash frozen in liquid nitrogen and stored in $-80{ }^{\circ} \mathrm{C}$ and were used for measurement of enzyme activities and other biochemical analysis.

\subsubsection{Enzyme extractions and assays}

Enzyme extractions were done at $4^{\circ} \mathrm{C}$. Liquid nitrogen was used to ground root samples to a powder and then samples were homogenized with $50 \mathrm{mM}$ Tris- $\mathrm{HCl}, \mathrm{pH}$ 7.8 buffer containing 2\% (w/v) PVPP, $0.1 \mathrm{mM}$ EDTA,
$0.1 \%(\mathrm{v} / \mathrm{v})$ Triton-X 100. For samples that will be used for measurement of APX activity, $5 \mathrm{mM}$ ascorbate was included in the homogenization buffer. Samples were centrifuged at $10.000 \mathrm{~g}$ for $10 \mathrm{~min}$. Following this, protein content and enzyme activities were measured from these supernatants. Protein levels were detected with Bradford method by using BSA as a standard [6].

SOD (EC 1.15.1.1) activity was assayed at $560 \mathrm{~nm}$ [7]. Enzyme amount that inhibits NBT photoreduction by $50 \%$ was defined as 1 unit of SOD. CAT (EC 1.11.1.6) activity was estimated by measuring the rate of decomposition of $\mathrm{H}_{2} \mathrm{O}_{2}$ at $240 \mathrm{~nm}$. Molar extinction coefficient of $43.6 \mathrm{M}^{-1} \mathrm{~cm}^{-1}$ was used for calculating decomposed $\mathrm{H}_{2} \mathrm{O}_{2}$ [8]. POX (EC 1.11.1.7) activity was measured with 3-3'-diaminobenzidine as substrate [9]. For measuring GR (EC 1.6.4.2) activity NADPH oxidation was followed at $340 \mathrm{~nm}$ [10]. APX (EC 1.11.1.11) activity was measured by following decrease in absorbance at $290 \mathrm{~nm}$, while ascorbate is oxidized [11]. NOX (EC 1.6.3. 1) activity was measured by monitoring XTT reduction at $470 \mathrm{~nm}$ [12]. Measurement of GST (EC 2.5.1.13) activity was done according to Habig et al. [13], which use 1-chloro-2,4dinitrobenzene (CDNB) as substrate.

\subsubsection{Identification of Antioxidant Isoenzymes}

Equal amounts of protein of each treatment group were separated with non-denaturing polyacrylamide gel electrophoresis (native-PAGE) [14]. $30 \mu \mathrm{g}$ protein of protein were loaded to each well. SOD isoenzymes were separated by using a $12.5 \%$ running gel. Gels were stained with solution containing NBT and riboflavin, then were illuminated with cool white florescent lamps until bands were visible [15]. GR and GST isoforms were separated by using a $7.5 \%$ running gel and stained according to given references $[16,17]$. NBT reduction was utilized for staining NOX isoenzymes that were separated on $10 \%$ running gels [2]. Gels were documented on a Vilber Lourmat imaging system. Following this, gels were analyzed with ImageJ software package. Gels were performed in three independent replicates.

\subsection{4. $\mathrm{H}_{2} \mathrm{O}_{2}$ measurement}

$\mathrm{H}_{2} \mathrm{O}_{2}$ was measured according to Özgür Uzilday et al. [2] Samples were extracted with ice-cold acetone containing $25 \mathrm{mM} \mathrm{H} \mathrm{H}_{4}$. $50 \mu \mathrm{l}$ of extract was combined with $950 \mu \mathrm{l}$ of reaction mixture $(100 \mu \mathrm{M}$ xylenol orange, $100 \mu \mathrm{M}$ sorbitol, $250 \mu \mathrm{M}$ ferrous ammonium sulfate and $1 \%$ ethanol (v/v)). Then, absorbance of the samples was measured at 550 and 800 nm. $\mathrm{H}_{2} \mathrm{O}_{2}$ levels were calculated by comparing the results to a standard prepared with known concentrations of $\mathrm{H}_{2} \mathrm{O}_{2}$.

\subsubsection{Lipid peroxidation}

Content of thiobarbituric acid reactive substances (TBARS) were measured as an indicator of lipid peroxidation levels [18]. 


\subsubsection{Statistical Analysis}

The experiments were conducted two times with with three independent replicates $(\mathrm{n}=6)$. Statistical significance of different treatment groups were analyzed with one-way analysis of variance (ANOVA) followed by Tukey post-test. $\mathrm{P}<0.05$ value were considered significant. Differences were shown with letters (a, b, c, d) in the figures. In all the figures, error bars represent standard error of the means (SEMO.

\section{Results and Discussion}

\subsection{Response of $\mathrm{O}_{2}{ }^{--}$related enzymes (SOD, NOX)}

SODs dismutate $\mathrm{O}_{2}{ }^{-}$to $\mathrm{H}_{2} \mathrm{O}_{2}$ and are as first line of defense against $\mathrm{O}_{2}^{--}$mediated oxidative stress. A remarkable increase in SOD activity was observed in cotton roots with decreasing $\mathrm{Mg}$ concentrations in the medium (Figure 1). Highest total SOD activity was observed in plants grown with $0 \mathrm{Mg}$, which was $46 \%$ higher than $1000 \mathrm{Mg}$ grown plants. Total of 3 different isoenzymes of SOD were observed in this work, each belonging to a different family of SOD, which are named according to the metal (MnSOD, FeSOD and $\mathrm{Cu} / \mathrm{ZnSOD}$ ) in their active site. Among these isoenzymes, FeSOD was not observed in $0 \mathrm{Mg}$ grown plants, while 75,150 and $1000 \mathrm{Mg}$ grown plants expressed all three isoenzymes. Increase in total SOD activity in 0 and $75 \mathrm{Mg}$ grown plants and alteration of isoenzyme pattern in $0 \mathrm{Mg}$ grown plants indicate a change in $\mathrm{O}_{2}^{--}$production dynamics in the cell. $\mathrm{Mg}$ deficiency increased the activity of SOD in rice seedlings [19]. In mulberry, $\mathrm{Mg}$ deficiency enhanced the SOD activity [5].
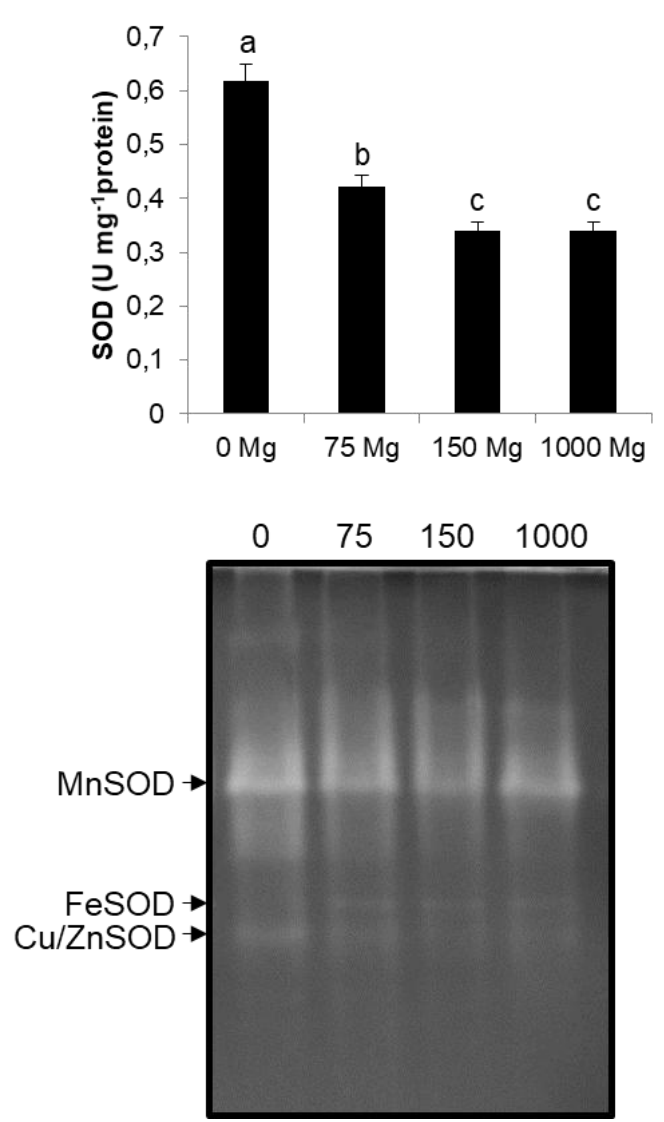

Figure 1. Total SOD activities and SOD isoenzmyes of roots treated with $0,75,150$ or $1000 \mu \mathrm{M} \mathrm{Mg}$.

NOXs plasma membrane localized enzymes that are produce ROS for signal purposes by transferring electrons from $\mathrm{NADPH}$ to $\mathrm{O}_{2}$ producing $\mathrm{O}_{2}{ }^{--} \mathrm{O}_{2}{ }^{--}$is converted to $\mathrm{H}_{2} \mathrm{O}_{2}$ both spontaneously and by apoplastic SODs. It has been demonstrated that resulting $\mathrm{H}_{2} \mathrm{O}_{2}$ acts as a signal for perception of environmental stimuli and also for regulation of gene expression [3]. In the current study, total NOX activity of roots drastically decreased with decreasing $\mathrm{Mg}$ concentrations (Figure 2). NOX activity of $0 \mathrm{Mg}$ grown plants were 3.5 fold lower when compared to $1000 \mathrm{Mg}$ plants and decrease in activity was correlated with decreasing $\mathrm{Mg}$ concentrations. Total of two NOX isoenzymes was detected in cotton roots. Among these, activity of NOX1 decreased with decreasing $\mathrm{Mg}$ concentrations and was lost in $0 \mathrm{Mg}$ treated plants. These results, when considered together with increased SOD activity in $0 \mathrm{Mg}$ plants, might indicate NOX enzyme activity decrease in response to increased oxidative load in the cell. 

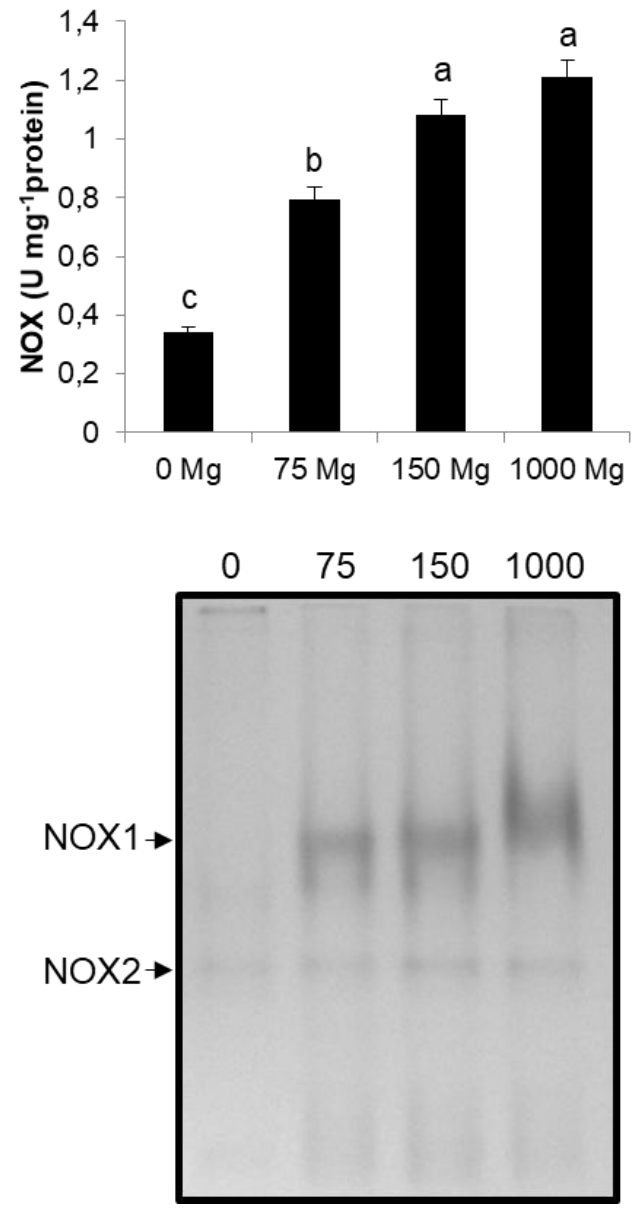

Figure 2. Total NOX activities and NOX isoenzmyes of roots treated with $0,75,150$ or $1000 \mu \mathrm{M} \mathrm{Mg}$.

\subsection{Response of $\mathrm{H}_{2} \mathrm{O}_{2}$ scavenging enzymes (CAT, POX, APX)}

$\mathrm{H}_{2} \mathrm{O}_{2}$ produced by dismutation of $\mathrm{O}_{2}{ }^{--}$can be detoxified by different class of peroxidases and CAT. In the current work, activities of CAT, POX and APX were measured and among these activities of CAT and POX were significantly responded to changing $\mathrm{Mg}$ in the medium (Figure 3). CAT activity was induced with increasing $\mathrm{Mg}$ concentrations and the highest CAT activity was observed in $1000 \mathrm{Mg}$ plants, which was approximately 3 fold higher when compared to $0 \mathrm{Mg}$ plant. On the other hand, POX activity was decreased with increased $\mathrm{Mg}$ in the medium and this activity in 0 $\mathrm{Mg}$ plants was 2.3 fold higher when compared to 1000 $\mathrm{Mg}$ plants. Among the $\mathrm{H}_{2} \mathrm{O}_{2}$ scavenging enzymes measured in this work APXs have the highest affinity for $\mathrm{H}_{2} \mathrm{O}_{2}$ and is an important component of antioxidant defense. There was no dose dependent response and 75, 150, $1000 \mathrm{Mg}$ grown plants had comparable APX activities, while APX activity decreased in $0 \mathrm{Mg}$ treated plants. This decrease was $41 \%, 40 \%$ and $34 \%$ when compared to 75,150 and $1000 \mathrm{Mg}$ grown plants, respectively. Moreover these results were consisted with Chou et al. [19] that the activities of CAT and APX were enhanced with $\mathrm{Mg}$ deficiency in rice seedlings. In addition, in mulberry plants, CAT activity was significantly inhibited with $\mathrm{Mg}$ deficiency while POX and APX activities were increased under $\mathrm{Mg}$ deficient conditions [5].
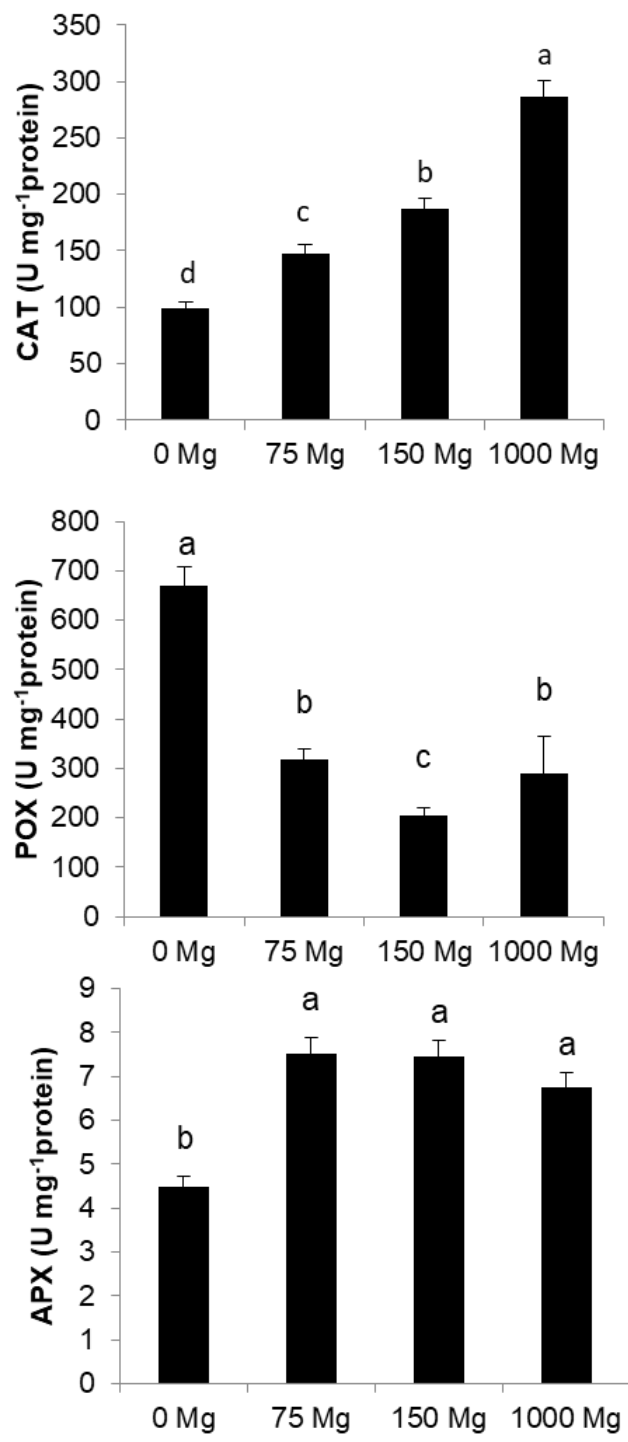

Figure 3. Total CAT, POX and APX activities of roots treated with $0,75,150$ or $1000 \mu \mathrm{M} \mathrm{Mg}$.

\subsection{Response of glutathione related enzymes (GR, GST)}

In order to support activity of APXs, oxidized ascorbate needs to be regenerated back to its reduced form. This is achieved by a set of enzymes, which collectively comprises Asada-Halliwell-Foyer cycle. GR is the last component of this cycle and it uses reducing power of $\mathrm{NADPH}$ to reduce oxidized glutathione (GSSG) to GSH, which again can be used to reduce dehydroascorbate to ascorbate [2]. In the current study, there were no statistically significant changes in GR activity of plants grown in differing $\mathrm{Mg}$ supply (Figure 4). Total of three isoenzymes of GR were observed in cotton roots and all three isoenzymes were expressed in all of the $\mathrm{Mg}$ concentrations used. Although total 
activity was not changed, GR1 isoenzyme was more prominent in $0 \mathrm{Mg}$ grown plants compared to plants grown in higher $\mathrm{Mg}$ concentrations. These results correlated with Polle et al. [20] that found that GR activity of Norway spruce was not affected from $\mathrm{Mg}$ deficiency. However, in rice seedlings, $\mathrm{Mg}$ deficiency increased GR activity [19].

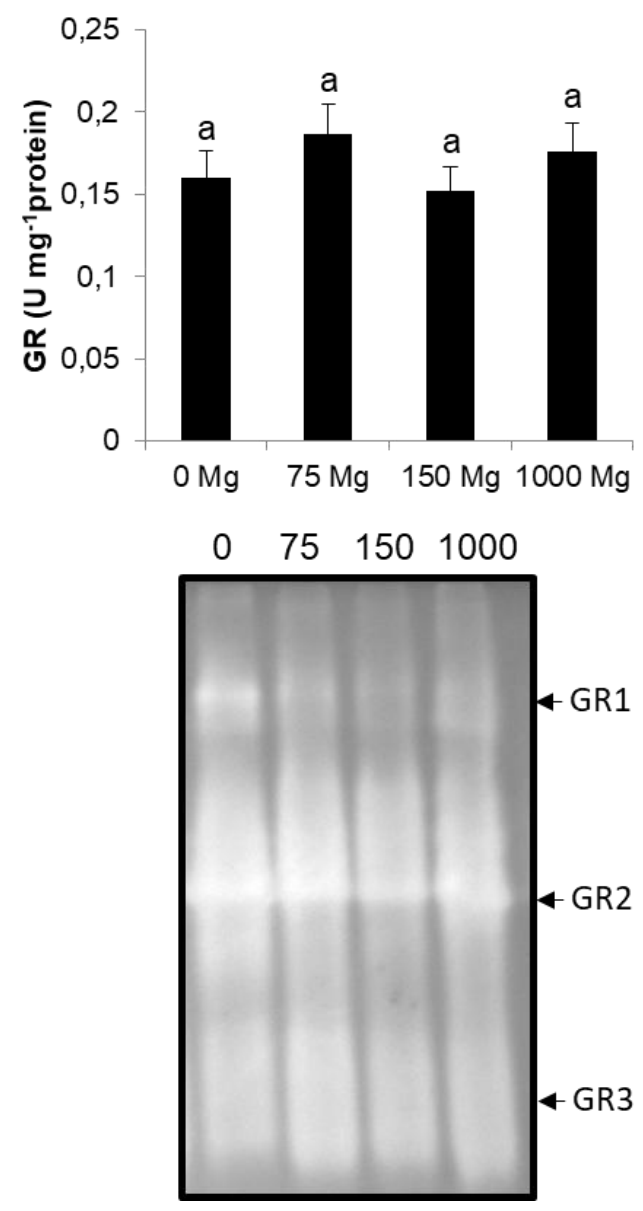

Figure 4. Total GR activity and GR isoenzymes of roots treated with $0,75,150$ or $1000 \mu \mathrm{M} \mathrm{Mg}$.

GSTs are enzymes with various functions that are vital for cellular detoxification reactions and oxidative stress tolerance [2]. In this work, similar to GR, total GST activity of cotton roots was not affected with varying $\mathrm{Mg}$ concentrations in the medium (Figure 5). Total of five GST isoenzymes was detected and among these GST5 was not observed in $0 \mathrm{Mg}$ grown plants, while GST1 was most intense in this group. This shift of isoenzymes (from GST5 to GST1) again indicates a change in ROS production dynamics, similar to SOD isoenzyme pattern.
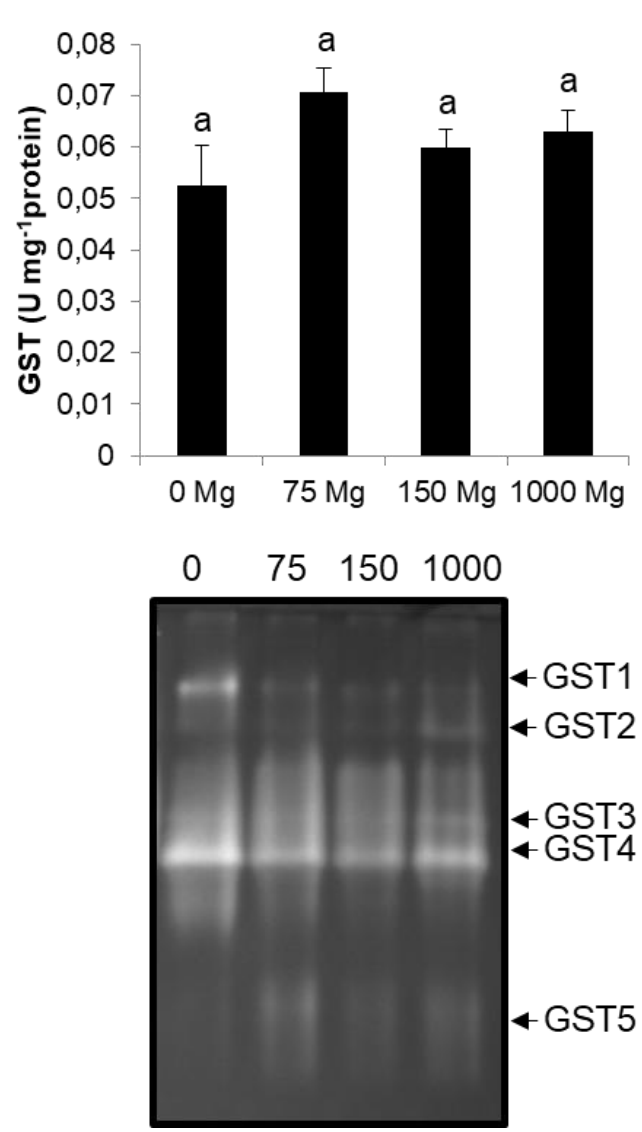

Figure 5. Total GST activity and GST isoenzymes of roots treated with $0,75,150$ or $1000 \mu \mathrm{M} \mathrm{Mg}$.

\subsection{Changes in oxidative stress related parameters (TBARS, $\mathrm{H}_{2} \mathrm{O}_{2}$ )}

$\mathrm{H}_{2} \mathrm{O}_{2}$ and TBARS levels are widely used as oxidative stress markers in the literature. $\mathrm{H}_{2} \mathrm{O}_{2}$ level is used as an indicator of ROS accumulation, while TBARS are evaluated as damage to lipid membranes by ROS, hence lipid peroxidation. In previous works, $\mathrm{Mg}$ deficiency enhanced the lipid peroxidation and $\mathrm{H}_{2} \mathrm{O}_{2}$ contents in rice seedlings [19]. In mulberry plants, $\mathrm{Mg}$ deficiency decreased TBARS content while it significantly enhanced the $\mathrm{H}_{2} \mathrm{O}_{2}$ levels [5]. It had been also known that lipid peroxidation was enhanced in $\mathrm{Mg}$ deficient maize [4]. In the current work, although remarkable changes both in total activities and isoenzyme patterns of antioxidant enzymes were observed, there were no changes in $\mathrm{H}_{2} \mathrm{O}_{2}$ accumulation levels and TBARS levels (Figure 6). These findings indicate that although ROS production dynamics change with $\mathrm{Mg}$ deficiency, antioxidant defense system was able to adapt to these changes and detoxify these ROS before membrane damage was observed. 

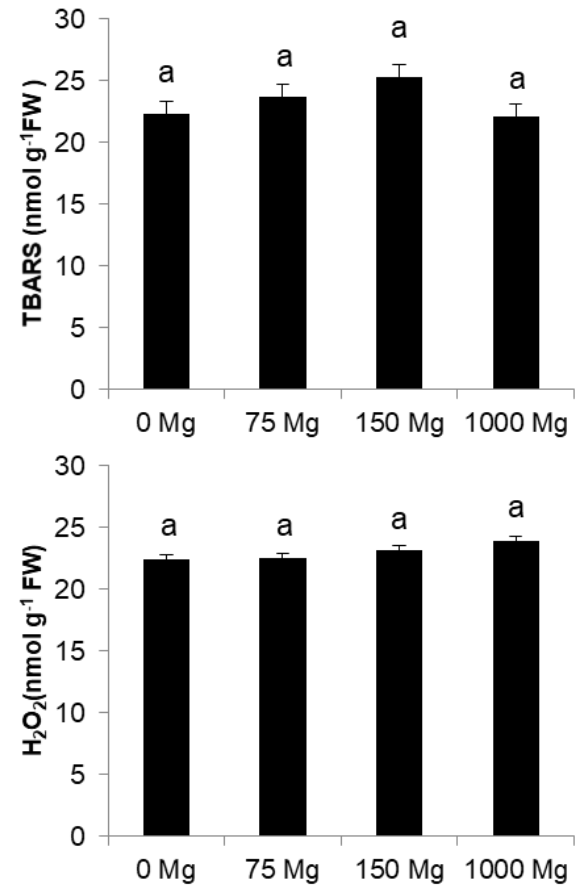

Figure 6. Lipid peroxidation (TBARS) and $\mathrm{H}_{2} \mathrm{O}_{2}$ levels of roots treated with $0,75,150$ or $1000 \mu \mathrm{M} \mathrm{Mg}$.

\section{Conclusion}

Findings of this work indicate that $\mathrm{Mg}$ deficiency does not cause oxidative load in roots of Gossypium hirsutum plants that overwhelms cellular antioxidant defence system, as evident by $\mathrm{H}_{2} \mathrm{O}_{2}$ and TBARS levels. However, to adjust to the new redox status, root cells drastically downregulate NADPH oxidase dependent ROS production and induced total SOD and especially MnSOD activity. These findings indicate that site of $\mathrm{O}_{2}$ production is mitochondria in root cells. Although, CAT and APX activities were decreased with $\mathrm{Mg}$ deficiency induced POX activity seems to limit $\mathrm{H}_{2} \mathrm{O}_{2}$ accumulation. These adaptive responses and changes in antioxidant defence was sufficient to prevent excess ROS accumulation and occurrence of oxidative damage in roots of Gossypium hirsutum plants under $\mathrm{Mg}$ deficiency.

\section{Ethics}

There are no ethical issues after the publication of this manuscript.

\section{References}

1. Cakmak, I, Yazici, AM. 2010. Magnesium: a forgotten element in crop production. Better Crops; 94: 23-25.

2. Özgür Uzilday, R, Uzilday, B, Yalcinkaya, T, Türkan, İ. 2017. $\mathrm{Mg}$ deficiency changes the isoenzyme pattern of reactive oxygen species-relatedenzymes and regulates NADPH-oxidase-mediated ROS signaling in cotton. Turkish Journal of Biology; 41(6): 868880 .

3. Mittler, R. 2017. ROS are good. Trends in Plant Science; 22(1): 11-19.
4. Tewari, RK, Kumar, P, Tewari, N, Srivastava, S, Sharma, PN. 2004. Macronutrient deficiencies and differential antioxidant responses - influence on the activity and expression of superoxide dismutase in maize. Plant Science; 166: 687-694.

5. Tewari, RK, Kumar, P, Sharma, PN. 2006. Antioxidant responses to enhanced generation of superoxide anion radical and hydrogen peroxide in the copper-stressed mulberry plants. Planta; 223: 1145-1153.

6. Bradford, MM. 1976. A rapid and sensitive method for the quantitation of microgram quantities of protein utilizing the principle of protein-dye binding. Analytical Biochemistry; 72: 248-254.

7. Beauchamp, C, Fridovich, I. 1971. Superoxide dismutase: improved assays and an assay applicable to acrylamide gels. Analytical Biochemistry; 44: 276-287.

8. Bergmeyer, HU. 1970. Methoden der enzymatischen Analyse. 2. Verlag Chemie.

9. Herzog, V, Fahimi, HD. 1973. A new sensitive colorimetric assay for peroxidase using 3, 3'-diaminobenzidine as hydrogen donor. Analytical Biochemistry; 55: 554-562.

10. Foyer, $\mathrm{CH}$, Halliwell, B. 1976. The presence of glutathione and glutathione reductase in chloroplasts: a proposed role in ascorbic acid metabolism. Planta; 133: 21-25.

11. Nakano, Y, Asada, K. 1981. Hydrogen peroxide is scavenged by ascorbate-specific peroxidase in spinach chloroplasts. Plant and Cell Physiology; 22: 867-880.

12. Jiang, M, Zhang, J. 2002. Involvement of plasma-membrane NADPH oxidase in abscisic acid-and water stress-induced antioxidant defense in leaves of maize seedlings. Planta; 215: 1022-1030.

13. Habig ,WH, Pabst, MJ, Jakoby, WB. 1974. Glutathione Stransferases the first enzymatic step in mercapturic acid formation. Journal of Biological Chemistry; 249: 7130-7139.

14. Laemmli, UK. 1970. Cleavage of structural proteins during the assembly of the head of bacteriophage T4. Nature; 227: 680-685.

15. Beauchamp, CO, Fridovich, I. 1973. Isozymes of superoxide dismutase from wheat germ. Biochimica et Biophysica Acta Protein Structure and Molecular Enzymology; 317: 50-64.

16. Hou, WC, Liang, HJ, Wang, CC, Liu, DZ. 2004. Detection of glutathione reductase after electrophoresis on native or sodium dodecyl sulfate polyacrylamide gels. Electrophoresis; 25(17): 2926-2931.

17. Ricci, G, Bello, ML, Caccuri, AM, Galiazzo, F, Federici, G. 1984. Detection of glutathione transferase activity on polyacrylamide gels. Analytical Biochemistry; 143: 226-230.

18. Heath, RL, Packer, L. 1968. Photoperoxidation in isolated chloroplasts: I. Kinetics and stoichiometry of fatty acid peroxidation. Archives of Biochemistry and Biophysics; 125: 189198.

19. Chou, TS, Chao, YY, Huang, WD, Hong, CY, Kao, CH. 2011. Effect of magnesium deficiency on antioxidant status and cadmium toxicity in rice seedlings. Journal of Plant Physiology; 168(10), 1021-1030.

20. Polle, A, Otter, T, Mehnejakobs, B. 1994. Effect of magnesiumdeficiency on antioxidative systems in needles of Norway spruce [Picea abies (L.) Karst.] grown with different ratios of nitrate and ammonium as nitrogen sources. New Phytologist; 128(4): 621628 . 